\title{
WAVELET TRANSFORM BASED BALL BEARING FAULT DETECTION SCHEME FOR HEAVY DUTY MINING ELECTRICAL MOTORS UNDER SUPPLY FREQUENCY REGULATION USING MCSA
}

\author{
Ashish Kumar Sinha ${ }^{1 *}$, Sukanta Das ${ }^{2}$, Tarun Kumar Chatterjee ${ }^{3}$ \\ ${ }^{1}$ Research Scholar, Department of Mining Machinery Engineering, Indian Institute of Technology \\ (Indian School of Mines) Dhanbad, Jharkhand. Pin-826004, India \\ ${ }^{2}$ Assistant Professor, Department of Electrical Engineering, Indian Institute of Technology (Indian \\ School of Mines) Dhanbad, Jharkhand. Pin-826004, India \\ ${ }^{3}$ Professor, Department of Mining Machinery Engineering, Indian Institute of Technology (Indian \\ School of Mines) Dhanbad, Jharkhand. Pin-826004, India
}

(Received: March 2017 / Revised: June 2017 / Accepted: January 2018)

\begin{abstract}
Most heavy duty mining electrical drives employ squirrel cage induction motors (SCIMs) which are subjected to various undesirable stresses. Therefore, condition monitoring of the SCIMs is indispensable for achieving production goals with minimum downtime in a fault-free working environment. Because bearing damage is the most frequently occurring fault in SCIMs, an effective fault detection scheme will aid in achieving production targets in an industrial mining scenario. In this regard, the present work intends to propose an effective fault monitoring algorithm, which is immune to supply frequency regulation, for the detection of ball bearing damage in an SCIM. Discrete Wavelet Transform (DWT) is used for the design of the fault detection scheme. Validation of the proposed scheme is done in a LabVIEW based laboratory interface. The complete analysis is carried out in MATLAB/ Simulink using a 5.5 kW, 3-phase, 415 V, 50 Hz SCIM.
\end{abstract}

Keywords: Bearing fault; Condition monitoring; Discrete wavelet transform; Squirrel cage induction motor

\section{INTRODUCTION}

Squirrel cage induction motors (SCIMs) form an integral part of heavy duty mining electrical drives due to their low cost of procurement, ruggedness and low maintenance requirement. Regardless of this, a variety of undesirable stresses, such as bearing damage, eccentric running, rotor bar faults, and winding damage can hamper the working behavior of induction motors (IMs) (Vas, 1999) (Sinha et al., 2016), especially in the hazardous and dusty working environment prevalent in the mining industry. Studies reveal bearing damage to be the most frequently occurring fault SCIMs (Group, 1985; Albrecht et al., 1986; Gritli et al., 2017). Under normal operating conditions, small fissures gradually propagate to the surface generating detectable vibrations and increasing noise levels, which result in a localized fatigue phenomenon known as flaking or spalling. This contaminates the lubrication and causes localized overloading over the entire circumference of the raceway (Eschmann et al., 1958) (Riddle, 1955). Other external causes of bearing fault include contamination, corrosion, improper lubrication, improper installation, or brinelling. Brinelling, which is the formation of

\footnotetext{
*Corresponding author's email: sinha.1990@gmail.com, Tel: +91-8084176696, Fax: +91326-2296563 Permalink/DOI: https://doi.org/10.14716/ijtech.v9i1.1507
} 
indentations in the raceways as a result of deformation caused by static overloading, exposes the bearings to vibrations while stationary (Eschmann et al., 1958). In addition, misalignment of the bearing can be caused by defective bearing installation.

Owing to such a wide range of ball bearing failure modes and causes in mines, condition monitoring becomes essential for increasing machinery availability, reducing consequential damage, and improving operational efficiency ( $\mathrm{Su} \&$ Chong, 2007; Choi et al., 2011). Mechanical vibration analysis techniques are commonly used to monitor the characteristic frequencies which are indicative of bearing damages to determine the condition of the bearing (Kumar et al., 2016). However, various studies demonstrate that stator current monitoring can provide the same indications without requiring access to the motor (Kliman \& Stein, 1990; Kliman \& Stein, 1992; Gritli et al., 2017). Vibration and current parameters, used for bearing condition monitoring, can also be analyzed using a variety of techniques. The most widely used being Fast Fourier Transform (FFT) and Discrete Wavelet Transform (DWT) (Eren \& Devaney, 2001; Singh \& Kazzaz, 2009). While the available literature extensively demonstrates the drawbacks associated with the use of FFT based analysis - the major concerns being its nonapplicability to non-stationary signal and transient analysis (Elkasabgy et al., 1992; Rodriguez et al., 2006; Siddiqui et al., 2015) - the implementation of DWT for the detection of bearing damage using starting current transient has been demonstrated (Eren \& Devaney, 2001). Furthermore, wavelet transform can be used for the isolation and detection of dry bearing damage (Singh \& Kazzaz, 2009). While the existing literature demonstrates the use of wavelet transform during startup transients, its applicability to signals under frequency regulation in steady state remains an unexplored area of research. Unfortunately, existing algorithms are in steady state remains an unexplored area of research. Unfortunately, existing algorithms are cumbersome, with sluggish execution - a condition which is exceedingly undesirable for infield fault diagnosis.

This paper demonstrates the feasibility of ball bearing fault detection using DWT of stator current to be used as a viable detection tool for a motor subjected to supply frequency regulation in steady state. Furthermore, the present work proposes a simple DWT-based fault detection scheme for finding bearing damage in SCIMs while being immune to supply frequency regulation in steady state. The simple nature of this method allows it to be quickly executed, which is essential for effective condition monitoring.

\section{EFFECT OF BALL BEARING FAULT ON STATOR CURRENT SPECTRUM}

Eccentric running of the motor due to faulty ball bearing causes anomalies in air gap flux density, which induces characteristic vibrations that can be seen on the stator current spectrum (Schoen \& Habetler, 1993; Gritli et al., 2017). This, in turn, affects the mutual inductances of the machine producing stator current harmonics with frequencies predicted by Equation 1 (Kliman \& Stein, 1990; Kliman \& Stein, 1992; Bindu \& Thomas, 2014).

$$
f_{e c c}=f_{e}\left[1 \pm k\left(\frac{1-s l}{p / 2}\right)\right]=\left|f_{e} \pm k \cdot f_{r m}\right|
$$

Furthermore, the mechanical displacement resulting from the damaged bearing causes the air gap of the machine to vary in a manner similar to a combination of rotating eccentricities moving in both clockwise and counterclockwise directions. These variations generate characteristic frequencies in stator current spectrum at $f_{b n g}$ which is related to the vibrational and electrical supply frequencies as given by Equation 2. 


$$
f_{b n g}=\left|f_{e} \pm m \cdot f_{v}\right|
$$

The characteristic frequencies of ball bearings depend on bearing dimensions (Figure 1).

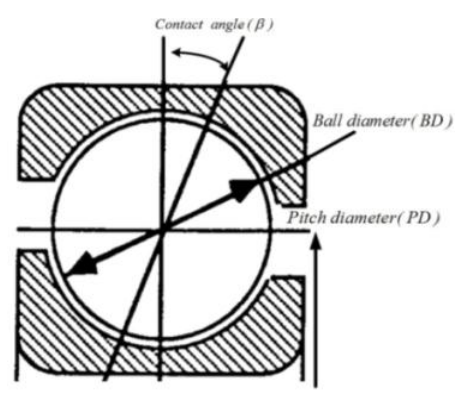

Figure 1 Ball bearing dimensions

In radially loaded bearings, the contact areas of the balls and raceways carry the heaviest loads causing most fatigue failures to involve these components (Mobley, 1990). The ball spin frequency is caused by the rotation of each ball about its center. Since a defect on a ball will contact both the inner and outer races during every revolution, the ball defect frequency, which is the cause of maximum damage in the bearings, is twice the spin frequency and can be written as Equation 3.

$$
f_{b}=\frac{P D}{B D} f_{r m}\left[1-\left(\frac{B D}{P D} \cos \beta\right)^{2}\right]
$$

\section{MODELING OF VARIABLE FREQUENCY FED SCIM AND BALL DEFECT}

This section presents the modeling and simulation of variable frequency fed SCIM and the modeling of ball bearing defect in the SCIM.

\subsection{D-Q Model of Squirrel Cage Induction Motor}

The induction machine d-q or dynamic equivalent circuit is shown in Figure 2. Krause's model, as detailed in (Krause, 1986), is one of the most popular induction motor models derived from this equivalent circuit. The flux linkage modeling equations are given as Equation 4.

$$
\begin{aligned}
& \frac{d F_{q s}}{d t}=\omega_{b}\left[v_{q s}-\frac{\omega_{e}}{\omega_{b}} F_{d s}+\frac{R_{s}}{X_{l s}}\left(F_{m q}+F_{q s}\right)\right] \\
& \frac{d F_{d s}}{d t}=\omega_{b}\left[v_{d s}-\frac{\omega_{e}}{\omega_{b}} F_{q s}+\frac{R_{s}}{X_{l s}}\left(F_{m d}+F_{d s}\right)\right] \\
& \frac{d F_{q r}}{d t}=\omega_{b}\left[v_{q r}-\frac{\left(\omega_{e}-\omega_{r}\right)}{\omega_{b}} F_{d r}+\frac{R_{r}}{X_{l r}}\left(F_{m q}-F_{q r}\right)\right] \\
& \frac{d F_{d r}}{d t}=\omega_{b}\left[v_{d r}-\frac{\left(\omega_{e}-\omega_{r}\right)}{\omega_{b}} F_{q r}+\frac{R_{r}}{X_{l r}}\left(F_{m d}-F_{d r}\right)\right]
\end{aligned}
$$




$$
\begin{aligned}
& F_{m q}=X_{m l}^{*}\left[\frac{F_{q s}}{X_{l s}}+\frac{F_{q r}}{X_{l r}}\right] \\
& F_{m d}=X_{m l}^{*}\left[\frac{F_{d s}}{X_{l s}}+\frac{F_{d r}}{X_{l r}}\right]
\end{aligned}
$$

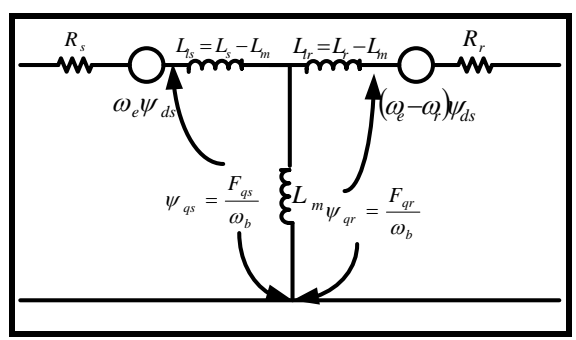

(a)

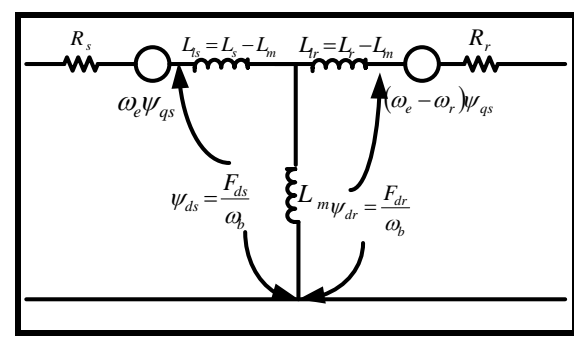

(b)

Figure 2 Krause's dynamic D-Q equivalent circuit of SCIM

The current and torque relations are given as Equations 5 and 6, respectively.

$$
\begin{gathered}
i_{q s}=\frac{1}{X_{l s}}\left(F_{q s}-F_{m q}\right) \\
i_{d s}=\frac{1}{X_{l s}}\left(F_{d s}-F_{m d}\right) \\
i_{d r}=\frac{1}{X_{l r}}\left(F_{q r}-F_{m q}\right) \\
i_{d r}=\frac{1}{X_{l r}}\left(F_{d r}-F_{m d}\right) \\
T_{e}=\frac{3}{2}\left(\frac{p}{2}\right) \frac{1}{\omega_{b}}\left(F_{d s} i_{q s}-F_{q s} i_{d s}\right) \\
T_{e}-T_{L}=J\left(\frac{2}{p}\right) \frac{d \omega_{r}}{d t}
\end{gathered}
$$

\subsection{Modeling of SCIM under Frequency Regulation}

Line current of a $5.5 \mathrm{~kW}$ SCIM running at the rated speed (1425 rpm at 5\% slip) is tapped out and scaled down (to 1/1000 of the original value) for DWT analysis. In practice the supply frequency varies within $49.2 \mathrm{~Hz}-50.3 \mathrm{~Hz}$ (i.e. roughly by $\pm 1.5 \%$ from $50 \mathrm{~Hz}$, as mentioned in Central Electricity Authority 2010 amendment).

In this work, a worst-case scenario of $\pm 4 \%$ regulation in the nominal frequency is generated by a slow varying sine wave of frequency $5 \mathrm{~Hz}$ and amplitude $2 \mathrm{~V}$ in each of the three phases to generate a non-stationary supply (Figure 3). This three-phase, $415 \mathrm{~V}$, non-stationary voltage is fed to the $5.5 \mathrm{~kW}$ SCIM as designed in MATLAB/Simulink using the D-Q model approach. 


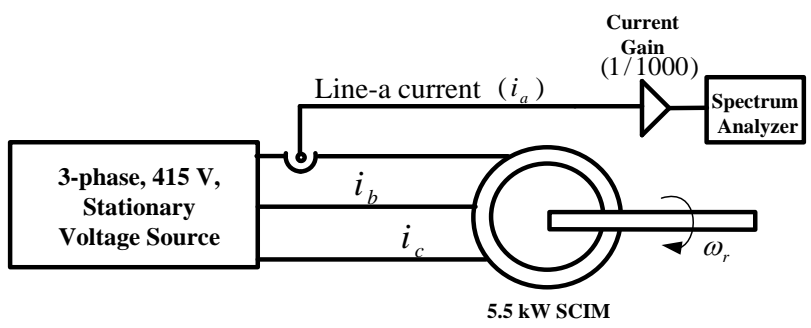

Figure 3 Block diagram in MATLAB/Simulink for variable frequency voltage fed SCIM

\subsection{Modeling of Ball Bearing Damage}

Ball bearing damage produces a radial motion between the rotor and stator of the machine. The mechanical displacement which results from the damaged bearing causes the air gap of the machine to vary in a manner that can be described by a combination of rotating eccentricities moving in both clockwise and counterclockwise directions. This eccentric movement of the rotor induces characteristic frequencies in the otherwise sinusoidal air-gap flux. These characteristic frequencies are calculated as per Equation $1(80 \mathrm{~Hz}$ and $20 \mathrm{~Hz}$ in the clockwise and counterclockwise direction, respectively, for $\mathrm{k}=1$, i.e. principle slot harmonic). The introduction of these characteristic frequencies in the flux linkage block is used in the odelling of ball bearing defects in the present work.

\section{SIMULATION AND ANALYSIS OF BALL DEFECT IN BEARING}

\subsection{DWT Based Analysis}

DWT decomposes a signal $X[n]$ into sub-bands known as detailed and approximated signals (Burrus \& Guo, 1998) which correspond to the different frequency bands (Taher \& Malekpour, 2011).

$$
X[n]=\sum_{j}\left[\mathrm{a}_{\mathrm{n}}\right] \Phi_{j}[n]+\sum_{n=1}^{L-1} \sum_{j}\left[\mathrm{~d}_{\mathrm{n}}\right] \Psi_{n, j}[n]
$$

The scaling function and the mother wavelet are defined as

$$
\begin{aligned}
& \Phi_{j}[n]=2^{1 / 2} \Phi(2 n-j)[\text { scale }=2, \text { shifted by ' } j \text { ' samples }] \\
& \Psi_{n, j}[n]=2^{L / 2} \Psi\left(2^{L} n-j\right)[\text { scale=2', shifted by ' } j \text { ' samples] }
\end{aligned}
$$

DWT can provide coincident time and frequency information for the spectrum. Therefore, DWT based Multi-Resolution Analysis can be effectively used as an on-line condition monitoring tool.

\subsubsection{Choice of sampling frequency for DWT based analysis}

Sampling frequency and the maximum number of decomposition levels determine the frequency bands corresponding to the detailed and approximated signals, $\left[0,2^{-(L+1)}\right]$ and $\left[2^{-(n+1)} F_{s}, 2^{-n} F_{s}\right]$ respectively (Taher \& Malekpour, 2011), at each level obtained by using MRA. The frequency bands for various sampling frequencies are given in Table 1. 
Table 1 Frequency bands of $\left[\mathrm{d}_{\mathrm{n}}\right] /\left[\mathrm{a}_{\mathrm{n}}\right]$ for various sampling frequencies

(Taher \& Malekpour, 2011)

\begin{tabular}{ccccc}
\hline \multirow{2}{*}[\mathrm{d}_{\mathrm{n}}]{$/\left[\mathrm{a}_{\mathrm{n}}\right]$} & \multicolumn{4}{c}{ Sampling Frequency $F_{S}(\mathrm{~Hz})$} \\
\cline { 2 - 5 } & 6200 & 6250 & 6300 & 6350 \\
\hline$\left[\mathrm{d}_{1}\right]$ & $1550-3100$ & $1562-3125$ & $1575-3150$ & $1588-3175$ \\
{$\left[\mathrm{~d}_{2}\right]$} & $775-1550$ & $781-1562$ & $788-1575$ & $794-1588$ \\
{$\left[\mathrm{~d}_{3}\right]$} & $388-775$ & $390-781$ & $394-788$ & $397-794$ \\
{$\left[\mathrm{~d}_{4}\right]$} & $194-388$ & $195-390$ & $197-394$ & $198-397$ \\
{$\left[\mathrm{~d}_{5}\right]$} & $97-194$ & $98-195$ & $97-197$ & $99-198$ \\
{$\left[\mathrm{~d}_{6}\right]$} & $48-97$ & $49-98$ & $49-98$ & $49-98$ \\
{$\left[\mathrm{~d}_{7}\right]$} & $24-48$ & $25-49$ & $25-49$ & $25-49$ \\
{$\left[\mathrm{~d}_{8}\right]$} & $12-24$ & $13-25$ & $13-25$ & $13-25$ \\
{$\left[\mathrm{a}_{8}\right]$} & $0-12$ & $0-13$ & $0-13$ & $0-13$ \\
\hline
\end{tabular}

The desired sideband frequencies (i.e., $94 \mathrm{~Hz}$ and $194 \mathrm{~Hz}$ as per Equations 2 and 3) in the line current spectrum for SCIM under ball bearing damage lie in $\left[\mathrm{d}_{6}\right]$ and $\left[\mathrm{d}_{5}\right]$ coefficients, respectively. This corresponds to sampling frequencies in the range $6200 \mathrm{~Hz}$ to $6350 \mathrm{~Hz}$. In practice, sampling frequency may not remain fixed owing to parameter variation in the sample. Any sampling frequency within the specified range is suitable for use in the proposed fault detection scheme. In the present work $6250 \mathrm{~Hz}$ was chosen as the sampling frequency.

\subsubsection{Choice of mother wavelet and number of decomposition levels}

The choice of a suitable mother wavelet is crucial for the proposed fault detection scheme. 'sym31' (correlation coefficient $=0.92$ with stator current) is suitable for the present work (Shashidhara \& Raju, 2013). Further, the maximum number of decomposition levels for the proposed scheme is obtained as follows (Shi et al., 2013):

$$
\begin{gathered}
L \geq \frac{\log \left(F_{s} / f_{e}\right)}{\log 2}+1 \\
L=n_{f}+2
\end{gathered}
$$

Based on Equations 10 and 11, it is found that 'sym31' with $8^{\text {th }}$ level decomposition satisfies the DWT of the stator current signal in the present work.

\subsubsection{Analysis of stator current signal}

The present work uses NSK 6208 ball bearings ( $P D=60 \mathrm{~mm}, B D=12 \mathrm{~mm}$ and $f_{r m}=30 \mathrm{~Hz}$ ). The characteristic vibration frequency for ball defect (calculated as per Equation 3) is $144 \mathrm{~Hz}$. This is reflected in the stator current spectrum at $94 \mathrm{~Hz}$ and $194 \mathrm{~Hz}$ around the principle slot harmonic (calculated as per Equation 2). Figure 4 shows $\left[\mathrm{d}_{n}\right]$ and $\left[\mathrm{a}_{\mathrm{n}}\right]$ for $8^{\text {th }}$ level decomposition of non-stationary phase-a current signal under both the healthy and faulty cases when the motor is operating at rated load torque (i.e. $35 \mathrm{Nm}$ ). The analysis shows that $\left[\mathrm{d}_{1}\right]-\left[\mathrm{d}_{4}\right]$ do not contain any substantial ripple due to the progressively smaller magnitude of the characteristic fault frequencies around higher order slot harmonics, while $\left[\mathrm{d}_{7}\right],\left[\mathrm{d}_{8}\right]$ and $\left[\mathrm{a}_{8}\right]$ represent the low frequency which do not affect the fault detection process (Figures 4a, 4b).

The presence of significant ripples in $\left[\mathrm{d}_{5}\right]$ and $\left[\mathrm{d}_{6}\right]$ (Figure $4 \mathrm{~b}$ ) is due to the presence of ball bearing fault frequencies $(194 \mathrm{~Hz}$ and $94 \mathrm{~Hz})$ around the fundamental frequency $(50 \mathrm{~Hz})$ of line current spectrum corresponding to frequency bands of $98-195 \mathrm{~Hz}$ and $49-98 \mathrm{~Hz}$ respectively 
(Table 2). Furthermore, Figure $4 a$ shows no variation of $\left[d_{5}\right]$ which indicates the absence of the upper sideband frequency $(194 \mathrm{~Hz})$ for the healthy case.

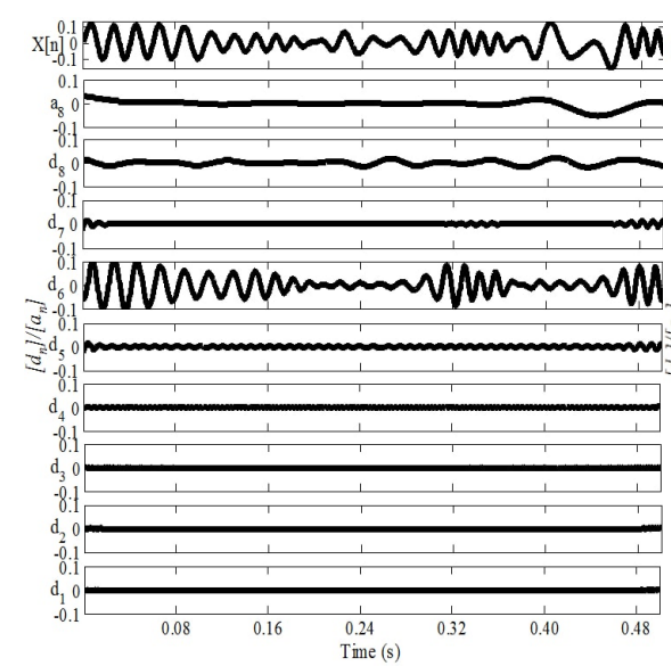

(a)

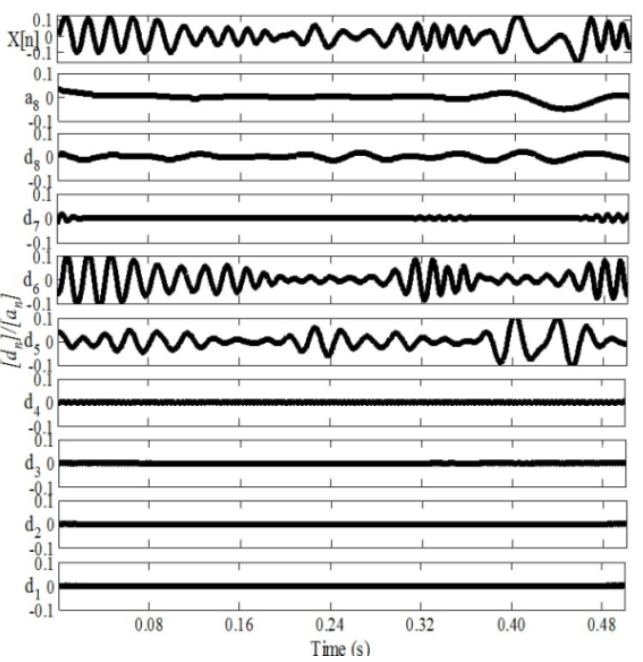

(b)

Figure $4\left[a_{n}\right]$ and $\left[d_{n}\right]$ obtained by DWT of phase-a current of $5.5 \mathrm{~kW} \mathrm{SCIM}$ at rated load torque under frequency regulation for: (a) healthy bearing, (b) damaged bearing

\section{MODELING OF DWT BASED FAULT DETECTION SCHEME}

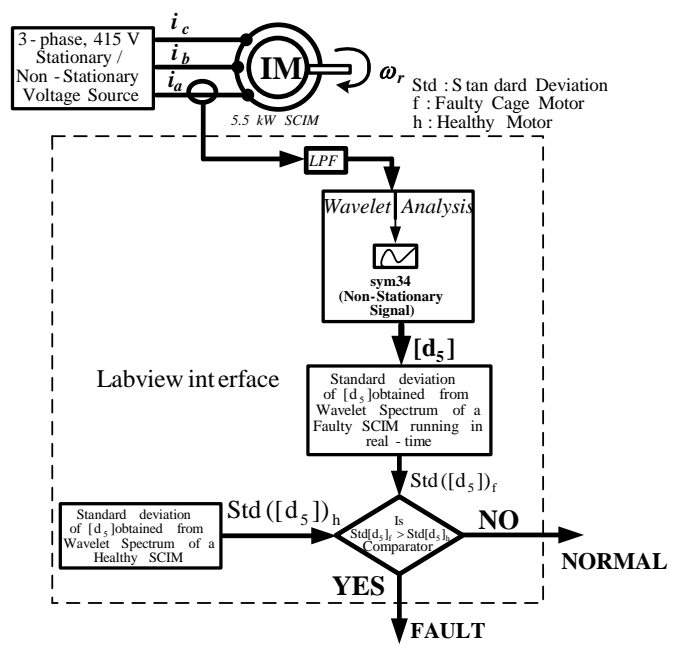

Figure 5 Scheme for DWT based bearing damage detection of SCIM

Figure 5 shows the scheme for DWT based ball bearing damage detection of SCIM. The SCIM is fed with a three phase, $415 \mathrm{~V}$ non-stationary source. The scaled down (1/1000) current of phase-a $\left(i_{a}\right)$ is used for DWT in the simulation study. 'sym31' is used for scrutinizing the nonstationary current signal in 'wavelet analysis' block. The point to point standard deviation of $\left[\mathrm{d}_{5}\right]$ obtained from the 'wavelet analysis' block is compared with the pre-fed values of standard deviation of $\left[\mathrm{d}_{5}\right]$, obtained by analyzing the motor in the healthy state in the 'comparator' block. The standard deviation of $\left[\mathrm{d}_{5}\right]$ obtained from the motor with damaged ball bearing running in real time is always higher than that of the motor in the healthy state which is indicative of the presence of fault. 


\section{REAL TIME VALIDATION}

This section details the real-time validation of the proposed bearing fault detection scheme in LabVIEW based SCIM laboratory interface.

\subsection{LabVIEW-based Laboratory Interface}

The LabVIEW-based laboratory prototype for ball bearing detection of $5.5 \mathrm{~kW}, 3$-phase, $415 \mathrm{~V}$, 4 pole SCIM and a damaged ball bearing is shown in Figure 6. The motor line current is sensed using a current sensor of LEM make in the Sensing module. This current is filtered, discretized, and digitized using an Analog to Digital converter in the data acquisition card (11V-30Vdc, 30 W) for feeding into the LabVIEW interface for analysis.

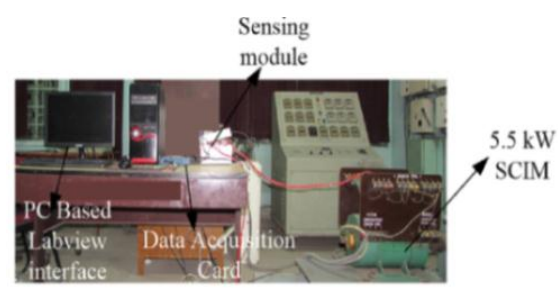

(a)

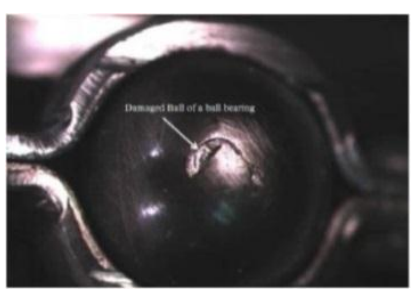

(b)

Figure 6 (a) Experimental setup of DWT based bearing damage detection of SCIM;

(b) damaged ball of NSK 6208 ball bearing

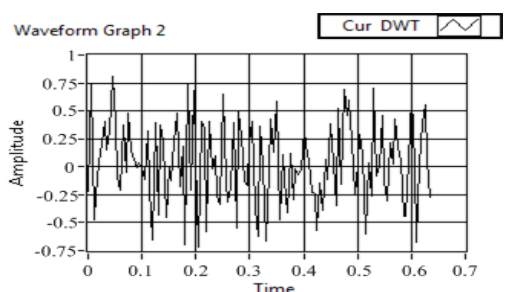

(a)

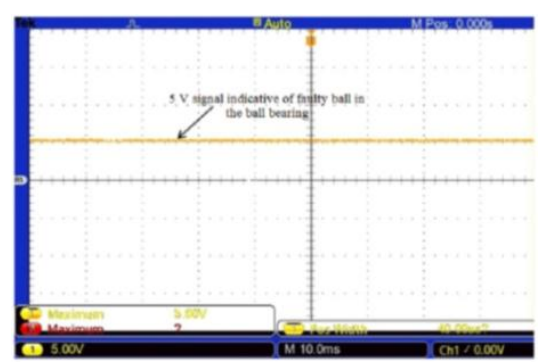

(c)

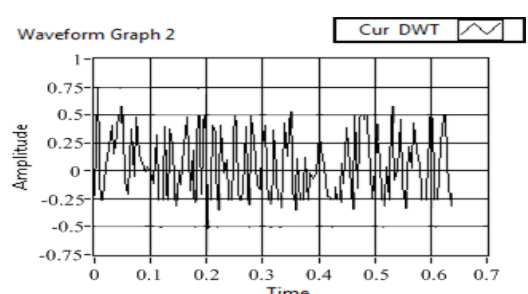

(b)

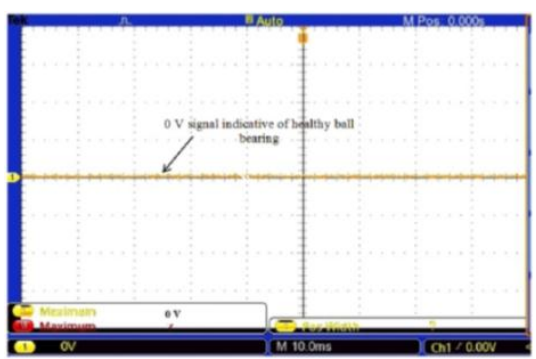

(d)

Figure 7 Experimental results: [ $\mathrm{d}_{5}$ ] coefficient of DWT spectrum for (a) a faulty bearing; (b) a healthy bearing; (c) $5 \mathrm{~V}$ signal for a faulty bearing; (d) $0 \mathrm{~V}$ fault signal for a healthy bearing

The real-time code for implementation of the bearing fault detection algorithm is generated in LabVIEW using a sampling frequency of $6.2 \mathrm{kHz}$ and the 'sym31' mother wavelet. As per the fault detection algorithm, aberration in standard deviation of [ $\mathrm{d}_{5}$ ] (Figure 7a) from pre-fed value (Figure 7b) gives a 5V signal (Figure 7c) in the Digital Storage Oscilloscope (DSO) as an indicator of a faulty bearing, whereas a healthy bearing, with no deviation from pre-fed values of $\left[\mathrm{d}_{5}\right]$ induces a $0 \mathrm{~V}$ signal in DSO (Figure $7 \mathrm{~d}$ ). Figure 7 validates the proposed bearing fault detection algorithm. 


\section{CONCLUSION}

The precarious working environment prevalent in mines increases the likelihood of damage to ball bearings. Quick detection is indispensable for reduced downtime of drive systems in underground mines. A DWT-based MRA of stator current for ball bearing damage detection is presented in the present work. The proposed fault detection scheme employs the standard deviation of level-five detailed coefficient $\left[\mathrm{d}_{5}\right]$ from the pre-fed values of the same for the detection of ball bearing damage, based on the careful choice of an analyzing mother wavelet ('sym 31 ' in the present work) and working sampling frequency ( $6.25 \mathrm{kHz}$ in the present work). The proposed scheme is further validated in real time by a LabVIEW based $5.5 \mathrm{~kW}$ SCIM laboratory interface. The proposed scheme is also robust to $\pm 4 \%$ (approx.) supply frequency regulation and $\pm 1.5 \%$ (approx.) sampling frequency variation at a given supply frequency. The implementation of this proposed approach requires a minimal instrumentation system, ideal for the grimy and hazardous mine environment.

\section{NOMENCLATURE}

\begin{tabular}{|c|c|c|c|}
\hline$p$ & Number of machine poles & $v_{d s}, v_{q s}$ & Stator voltage d-q component \\
\hline$f_{e}$ & Supply frequency $(\mathrm{Hz})$ & $v_{d r}, v_{q r}$ & Rotor voltage d-q component \\
\hline$f_{b n g}, f_{v}$ & $\begin{array}{l}\text { Characteristic frequency of current \& } \\
\text { vibration }(\mathrm{Hz})\end{array}$ & $F_{m q}, F_{m d}$ & $\begin{array}{l}\text { Magnetizing flux linkage d-q } \\
\text { component }\end{array}$ \\
\hline$s l$ & Machine slip & $R_{s}, R_{r}$ & Stator and rotor resistance \\
\hline$f_{e c c}$ & $\begin{array}{l}\text { Characteristic frequency for } \\
\text { eccentricity }(\mathrm{Hz})\end{array}$ & $X_{l s}, X_{l r}$ & Stator and rotor leakage reactance \\
\hline$f_{r m}$ & Mechanical rotor speed $(\mathrm{Hz})$ & $i_{d s}, i_{q s}$ & Stator current d-q component \\
\hline$k, m$ & $1,2,3, \ldots$ integer & $i_{d r}, i_{q r}$ & Rotor current d-q component \\
\hline$f_{b}$ & Ball defect vibration frequency & {$\left[d_{n}\right],\left[a_{n}\right]$} & Approx. and detail coeffs. \\
\hline$\omega_{e}, \omega_{b}, \omega_{r}$ & $\begin{array}{l}\text { Stator, motor and rotor angular } \\
\text { electrical frequency }\end{array}$ & $T_{e}, T_{L}$ & $\begin{array}{l}\text { Electromagnetic and load torque } \\
(\mathrm{rad} / \mathrm{s})\end{array}$ \\
\hline$\beta$ & Contact angle of balls \& races & $\Phi, \Psi$ & Scaling function., mother wavelet \\
\hline$d, q$ & Direct and quadrature axis & $n$ & Discrete sample number \\
\hline$s, r$ & Stator and rotor variable & $J$ & Moment of inertia (kg-m2) \\
\hline$P D, B D$ & Bearing pitch and ball diameter & $F_{S}$ & Sampling frequency $(\mathrm{Hz})$ \\
\hline$F_{i j}$ & Flux linkage $(i=q, d$ and $j=s, r)$ & $L$ & No. of decomposition levels \\
\hline$X_{m l}^{*}$ & $1 /\left(\frac{1}{X_{m}}+\frac{1}{X_{l s}}+\frac{1}{X_{l r}}\right)$ & $n_{f}$ & $\begin{array}{l}\text { Decomposition level containing } \\
\text { supply frequency }\end{array}$ \\
\hline
\end{tabular}

\section{REFERENCES}

Albrecht, P.F., Appiarius, J.C., McCoy, R.M., Owen, E.L., Sharma, D.K., 1986. Assessment of the Reliability of Motors in Utility Applications - Updated. IEEE Transactions on Energy Conversion, Volume EC-1(1), pp. 39-46

Bindu, S., Thomas, V.V., 2014. Diagnoses of Internal Faults of Three Phase Squirrel Cage Induction Motor - A Review. In: International Conference on Advances in Energy Conversion Technologies (ICAECT). Manipal, India, pp. 48-54

Burrus, C.S., Guo, H., 1998. Introduction to Wavelets and Wavelet Transforms: A Primer. Prentice Hall, USA 
Choi, S. Akin, B., Rahimian, M.M., Toliyat, H.A., 2011. Implementation of a Fault-diagnosis Algorithm for Induction Machines based on Advanced Digital-signal-processing Techniques. IEEE Transactions on Industrial Electronics, Volume 58(3), pp. 937-948

Elkasabgy, N.M., Eastham, A.R., Dawson, G.E., 1992. Detection of Broken Bars in the Cage Rotor on an Induction Machine. IEEE Transactions on Industry Applications, Volume 28(1), pp. 165-171

Eren, L., Devaney, M.J., 2001. Motor Bearing Damage Detection via Wavelet Analysis of the Starting Current Transient. In: IEEE Instrumentation and Measurement Technology Conference. Budapest, pp. 1797-1800

Eschmann, P., Hasbargen, L., Weigand, K., 1958. Ball and Roller Bearings: Their Theory, Design, and Application. K.G. Haydon \& Co. Ltd, London, UK

Gritli, Y., Bellini, A., Rossi, C., Casadei, D., Filippetti, F., Capolino, G.-A., 2017. Condition Monitoring of Mechanical Faults in Induction Machines from Electrical Signatures: Review of Different Techniques. In: $11^{\text {th }}$ International Symposium on Diagnostics for Electrical Machines Power Electronics and Drives (SDEMPED). Tinos, Greece, pp. 77-84

Group, I.M.R.W., 1985. Report of Large Motor Reliability Survey of Industrial and Commercial Installations, Part I. IEEE Transactions on Industry Applications, Volume IA21(4), pp. 853-864

Kliman, G.B., Stein, J., 1990. Induction Motor Fault Detection via Passive Current Monitoring. $I n$ : Proceedings of the International Conference on Electric Machines. Cambridge, MA, pp. $13-17$

Kliman, G.B., Stein, J., 1992. Methods of Motor Current Signature Analysis. Electric Machines and Power Systems, Volume 20(5), pp. 463-474

Krause, P.C., 1986. Analysis of Electric Machinery. McGraw-Hill Book Company, USA

Kumar, P., Sinha, A.K., Chatterjee, T.K., 2016. An Assessment of Vibration Monitoring as an Effective Tool for Induction Motor Condition Monitoring and Fault Diagnosis: A Brief Review. International Journal of Control Theory and Applications, Volume 9(41), pp. 407-416

Mobley, R.K., 1990. An Introduction to Predictive Maintenance. Van Nostrand Reinhold, New York, USA

Riddle, J., 1955. Ball Bearing Maintenance. University of Oklahoma Press, Norman, Oklahoma Rodriguez, P.J., Belahcen, A., Arkkio, A., 2006. Signatures of Electrical Faults in the Force Distribution and Vibration Pattern of Induction Motors. IEE Proceedings: Electric Power Applications, Volume 153(4), pp. 523-529

Schoen, R.R., Habetler, T.G., 1993. Effects of Time Varying Loads on Rotor Fault Detection in Induction Machines. In: Conference Record of the $28^{\text {th }}$ Annual IAS Meeting. Toronto, Ontario, Canada, pp. 324-330

Shashidhara, S.M., Raju, P.S., 2013. Tradeoff Analysis of Wavelet Transform Techniques for the Detection of Broken Rotor Bars in Induction Motors. Advance in Electronic and Electric Engineering, Volume 3(8), pp. 1019-1030

Shi, P., Chen, Z., Vagapov, Y., 2013. Wavelet Transform Based Broken Rotor-bar Fault Detection and Diagnosis Performance Evaluations. International Journal of Computer Applications, Volume 69(14), pp. 36-43

Siddiqui, K.M., Sahay, K., Giri, V.K., 2015. Detection of Bearing Fault in Inverter Fed Induction Motor by Transformative Techniques. In: Annual IEEE India Conference (INDICON). New Delhi, India, pp. 1-6

Singh, G.K., Kazzaz, S.A.S.A., 2009. Isolation and Identification of Dry Bearing Faults in Induction Machine using Wavelet Transform. Tribology International, Volume 42, pp. 849-861 
Sinha, A.K., Das, S., Chatterjee, T.K., 2016. A Case Study of bearing Fault Monitoring Techniques for Induction Motors. Journal of Mines, Metals and Fuels, Volume 64(5\&6), pp. 249-255

Su, H., Chong, K.T., 2007. Induction Machine Condition Monitoring using Neural Network Modeling. IEEE Transactions on Industrial Electronics, Volume 54(1), pp. 241-249

Taher, S.A., Malekpour, M., 2011. A Novel Technique for Rotor Bar Failure Detection in Single-cage Induction Motor using FEM and MATLAB/SIMULINK. Mathematical Problems in Engineering, Volume 2011, pp. 1-14

Vas, P., 1999. Parameter Estimation, Condition Monitoring, and Diagnosis for Electrical Machines. Clarendon, Oxford, UK 